\title{
On the Role of the Professor in Creating a Positive Learning Environment
}

Dr. Waddah Akili, Iowa State University 


\title{
On the Role of the Professor in Creating a Positive Learning Environment
}

\begin{abstract}
The paper focuses on the role of a "caring" faculty who believes that being a dedicated, thoughtful, and passionate is as important as being professionally competent. It is argued that faculty members can improve the quality of teaching by becoming more sensitive to students' needs even if the faculty member is not fully committed to modern teaching/learning methods. A caring faculty understands, encourages and supports students' individuality and is willing to listen and provide advice. The paper discusses the role of the "caring" professor in creating a positive environment where students feel comfortable being themselves and enjoying and appreciating the total experience of learning. The paper addresses relevant topics that supports teacher-students' relations, and as a consequence, improves the learning environment. The aforementioned topics include: the development of critical rationale for good teaching, taking account of learning styles, how to teach responsively, and recommended steps to build trust with students. In this type of environment students feel that they are important, that their needs can be met, and that others experience joy and satisfaction in helping them get their needs met. It is also argued that when the teacher is able to focus on assisting the students in meeting their needs, teacher's own needs get met. In concluding, the author presents his own reflections based on his experience as an engineering student and a faculty member. The author has a firm conviction that the only professor who belongs in a classroom is a caring professor.
\end{abstract}

\section{Introduction}

A caring faculty understands, encourages and supports students' individuality and is sensitive to students' needs. A caring faculty understands that the concept of individuality manifests itself in- among other things- different learning styles, visions, interests, and aspirations. In addition, a caring college faculty realizes that intelligence is not always the most significant factor in students' performance; and some other factors such as willingness and ability to focus, concentration and communication- may be even more important, and are a function of students' emotional well-being. A caring faculty supports individuality not only with encouragement and understanding, but also by not trying to mold students to an image of what they "should be" and how they "should behave". Instead, students should be encouraged to realize their own visions and expectations, rather than the expectations of others. ${ }^{(1,2)}$

A caring college professor helps his /her students by insuring that that they gain the self confidence to be themselves and exploit their uniqueness, to be successful, by helping them develop the necessary technical skills, and the social and emotional skills they require in their college years and beyond. The faculty member is gentle and sensitive about students' emotions, especially fear from new experiences and fear of failure. A 
caring college faculty fosters curiosity which is essential for gaining knowledge. Thus, faculty members have to realize and acknowledge that they are humans themselves, and it is all right to make mistakes. Also, caring faculty should acknowledge that in many situations there is no "right" or "wrong" way, but ought to show better approaches or solutions, rather than emphasizing what the student has done "wrong". In essence, the faculty should provide guidance and feedback instead of criticism. However, it is part of the professor's craft to learn how to give advice that does not undermine student's basic values as an individual. But avoiding it altogether is basically saying to the student: "I do not care about you". The positive alternative is to let the student know - when there is a pressing need - what may have gone wrong, and what could be done to rectify it. A caring professor also believes in discipline. The discipline that protects and safeguard the process of acquiring the skills and attitudes necessary for taking care of ourselves and others, based on self-esteem. ${ }^{(1,2)}$ Fear, shame and ridicule have no place in the classroom. Discipline provides students with the necessary set of tools they need to overcome their life-long problems.

\section{Developing a Critical Rationale for Good Teaching}

A critical rationale is a set of values, beliefs, and convictions about the essential forms and fundamental purposes of teaching. ${ }^{(3,4)}$ Embedded in this rationale are criteria for judging to what extent one's teaching exhibits features that he/she feels are essential to good teaching. At the center of a critical rationale is the distinctive set of aims towards which teacher's efforts are geared. ${ }^{(3,4)}$ These aims and purposes provide an organizing vision of where the teacher is going and why he /she are going there that can be presented to students and one's self with conviction, passion and clarity.

For a faculty in the classroom, a critical rationale functions in much the same way as a computerized navigation instruments do for an air or sea pilots in the midst of a storm. Such devices help maintain a sense of direction and stability even in the midst of turbulence and confusion. Calling upon a critical rationale at times of crisis-such as one's first encounter with the classroom environment- is one way to keep one's sense of himself /herself as a teacher intact. Developing such a rationale to guide one's practice is crucial for several domains of one's journey as a teacher: the personal vision, the political setting, the professional commitment, and the pedagogical measures. ${ }^{(3,5)}$

Personal vision: Often, the ambiguity of teaching, the feeling that things are not on track, and the emergence of unanticipated factors and situations can be extremely debilitating. At those times when the teacher feels that he /she is no longer in control and others (be it learners, colleagues, or superiors) are in charge of his/her plans, actions, and destiny. It can be dangerous and humiliating for the teacher to feel that he /she are off track, particularly when others step in to define his/her roles, aims, and functions. It may also be frustrating to realize that he/ she are devoting lots of time and tremendous energies with little or no positive outcome. However, with an organizing vision, the teacher is less likely to suffer from these feelings of uncertainty. A clear sense of purpose helps the teacher to endure periods of directionless confusion. During these periods the teacher can resolve to conserve his /her energies for the time when pursuing his/her vision is more possible. Also, should think about how he /she might realize aspects of 
his/her vision in smaller, more contained ways. So, a distinctive organizing vision - a clear picture why the teacher is doing what he /she is doing and can call up at points of crisis- is crucial to teacher's personal sanity and morale. ${ }^{(3,5)}$

Political setting: The teacher sooner or later may find himself /herself under pressure from figures in his /her institution requesting that they do things (such as accepting poorly developed curricula, adopting ineffective teaching methods, implementing irrelevant evaluation criteria, or be supportive of bad decisions) that he /she finds inappropriate and immoral. Some times there is little one can do short of quitting. Most of the times, however, one can argue against the wishes of institutionally powerful figures relying on his /her own knowledge, foresight, and distinctive organizing vision. When facing pressures from above, it is enormously helpful to be able to express one's opposition in terms of confidently articulated rationale based on knowledge, reasoning, and understanding. The teacher may or may not win the case. However, he /she is more likely to communicate a sense of clear-headedness, and relates a position grounded in a well developed and carefully conceived philosophy of practice. Such an approach is not likely to be interpreted as sheer personal stubbornness. To the contrary, it is more likely to gain the respect of others for his/her thoughtfulness and commitment, which is important for one's self-esteem and political well-being. ${ }^{(3,5,6)}$

Collective identity: A commitment to shared rationale for teaching is important for the development of a collective identity and, hence, for the development of professional strength among teachers. Most teachers work within contexts that are defined by the pursuit of particular objectives. Most teachers believe that no one does exactly what they do, and therefore decide that they have little in common with other teachers in other settings or content areas, and what they do has little impact beyond their educational enclaves. If teachers define themselves only as content or skill experts within some restricted domain, they effectively cut themselves off from a broader identity as agents involved in helping students shape the world they live in. What is needed to counter this tendency towards isolation is an underlying rationale for college teaching that acknowledges the importance of specialist curricula, skills and expertise, but at the same time, would go beyond these to help unite college teachers who are in different domains to pursue shared purposes. The inclination, vision and capacity to create one's own values, meanings, and environment is developed chiefly through cooperation and sharing of plans and efforts with others who, most likely, are teachers in different settings and domains. ${ }^{(5)}$

Pedagogical measures: Possessing a clear rationale for the practice is, of course, pedagogically important. Knowing what the aims of one's teaching are helps the teacher to judge whether or not he /she has the influence he /she wishes. It helps immeasurably in evaluating one's efforts if he /she has a clear vision of what is believed to be the fundamental forms and purposes of college teaching. Evaluations and judgment expressed by administrators and employers are often different from our own, and do remind us that poor evaluations mean nothing more than that others are judging our efforts and performance by criteria that are, most likely, contradictory to our own rationale. Therefore, we should reject such evaluations, even at the expense of whether we keep the job and /or get promoted. So, developing a clear rationale for the practice, 
and being able to say to yourself, "Even though others do not understand why I am doing what I do, but I am confident that it is right for me and my students"- it is an important state of mind that teachers need to protect themselves against the temporary debilitations of such unfair evaluations. ${ }^{(5,6)}$ One of the most important things that the teacher ought to keep in mind is how the actions he /she are taking, and the choices he /she are making, connect to the overall aims that he /she are pursuing.

Students' legitimate concerns: If faculty's teaching is grounded in a well-conceived rationale, he/she will find out that this has powerful effect on the students. At times of uncertainty, students will draw strength from teacher's knowledge, passion, and conviction. Students have the right to ask the teacher to explain why he/she wants them to do something in a specific way. They may be concerned that the content you proposed to cover is irrelevant, the learning method you favor is inappropriate, or the criteria applied to judging their efforts are unfair. In response to such legitimate concerns, the teacher needs to demonstrate to students that he/she knows what he /she is doing. Even if some students may not agree with teacher's explanations and justifications, they will be reassured when the teacher can express these (explanations and justifications) clearly and confidently.Studetns do draw comfort from the fact that the teacher knows what he /she is doing, and what's is happening is valuable and in the interest of the students.

Undoubtedly, demonstrating that the teacher has a carefully developed and deeply felt conviction about the importance of his/her approach to teaching/learning is an important element of the credibility students seek in their teachers. ${ }^{(5)}$

An underlying rationale for the practice (teaching and related duties), an organizing vision for teaching, critically responsive teaching-may seem abstract and remote concepts and far out from everyday practice. But the reality is that: Nothing could be further from the truth. Even if some teachers disagree with this rationale, they can not deny that being clear about why they are teaching is important to them and to those around them. It is not sufficient for the teacher to accept whichever rationale imposed upon him /her by the employer at any particular time or place, or to follow the pedagogic fashions of the moment. This may work for a while and may even convince one's self as well as students and colleagues, that one's practice is grounded in strongly felt and carefully conceived convictions. But to one's dismay, and sooner or later, the employers may change and pedagogic fashions will change as well. Then the teacher will realize that the convictions he/she thought were solid are, in reality, opaque and insubstantial. ${ }^{(5)}$ Undoubtedly, this is demoralizing to say the least, and its adverse effects may spread to those around. The remedial measure is for the teacher to think long and hard about the values, beliefs, and convictions by which he /she wants his /her efforts to be guided. The benefits that could be gained from such reflections are substantial. Teacher's practice will be more focused and will imbue students with a sense of confidence in his /her foresights and abilities.

\section{Taking Account of Learning Styles}

Teaching is effective when it recognizes students' various learning styles, teaching to stimulate students, and engage them in the learning process. The term "learning style" may be described as: "biologically and developmentally imposed set of personal characteristics that make some teaching (and learning) methods effective for certain 
people but ineffective for others."(7) Various models of learning style preferences have been described. The most prominent ones are: the Myers-Briggs Type Indicator, referred to as: the MBTI ${ }^{(8)}$, Kolb's Learning Style Model ${ }^{(9)}$, the Felder-Silverman Learning Style Model ${ }^{(10)}$, and the Dun and Dun Learning Style Model. ${ }^{(11)}$

The MBTI, based on Jung's theory, has been popular in explaining differences in learning for normal people. The dimension of most interest for learning is sensing (S) versus intuitive $(\mathrm{N})$ type. ${ }^{(12)}$ The sensing person prefers a straightforward, logical, stepby-step approach to learning. The sensing person, often learns by solving problems, and tends to find theory difficult. The intuitive individual, on the other hand, will skip steps and follow hunches. He /she learns from theory and tends to do a minimal number of problems because they think they understand without having to solve problems. ${ }^{(13)}$

Perry's Model of College Student Development ${ }^{(14)}$ can also be used to monitor student learning. According to this model, which consists of nine positions (i.e., stages), occupying four general outlooks; people progress from positions 1 and 2, (dualistic), right versus wrong orientations to multiplicity (positions 3 and 4), where multiple answers are possible. Positions 5 and 6 are assigned to relativism where the person realizes that the world is relative with right versus wrong being a special case. Finally, people may reach stages 7,8 , and 9- these three stages represent commitment to value within relativism. Generally, students move up the scale (i.e., from 2 or 3 to 4 and 5) with gaining knowledge, maturity and experience.

Another useful way of considering student learning is to look at deep versus shallow approaches to learning. ${ }^{(15,16)}$ These two terms that describe learning, stem from a research in Sweden. ${ }^{(12)}$ Also, deep approach to learning has been connected to chemical changes in the brain which may result in lasting changes in cognition, attitude and character structure. In the shallow approach, students focus on learning isolated tasks often through memorization. The student's goal is to be able to reproduce information; and, as such, does not focus on understanding but rather on superficial form. In the deep approach to learning, students focus on determining the meaning of what they are learning and learning how to connect information, which makes the learning holistic. Students who are intrinsically motivated prefer a deep approach, while extrinsically motivated students prefer a shallow approach. Almost every one is capable of using either deep or shallow approach to learning; however, people do have preferences. Those who prefer a shallow approach may find deep approach difficult. And those who are forced to use a shallow approach to learning would be annoyed and dissatisfied. ${ }^{(12)}$

Some engineering educators argue in favor of adopting a learning style approach within a variety of teaching strategies ${ }^{(17)}$, while others have preferred to look at the psychological implications of learning styles in specific educational domains. ${ }^{(18)}$ The author is of the opinion that engineering educators, today, should not overlook the extensive research that exists on learning styles. Educators should try to keep up with research development in the arena of learning /teaching styles, and attempt to use it whenever possible. To start, a caring instructor who is interested in developing his/her classroom skills should begin by discovering his/her own learning style. An interesting question is: How does the way you learn influence the way you teach? It is equally important to contemplate different 
approaches to accommodate different learners, particularly after having learned about one's own learning style. An instructor with some understanding of differences in students' learning styles is well on his /her way in making his /her teaching more effective. ${ }^{(19)}$

A viable learning style model must be grounded in research, periodically evaluated, and adapted to reflect the developing knowledge base. ${ }^{(11)}$ Implementation of learning style practices must conform to accepted standards of ethics, and be carried out by competent instructors, who can provide suitable activities that appeal to each learning style. To promote effective learning, within the context of varied learning styles, it is important to form groups within the class. How do you form effective groups? How do you make groups work? What do groups do? The answers to these questions will differ from one course to another, depending on: course type, course content, course level, prevailing culture, available resources, and applicable guidelines.

Research has shown that some learners have to express themselves openly in the class, and do desire personal interaction with the instructor and their fellow students. This type can forge ties easily with others, and sees his /her work and the outcome through the "group". They are excellent participants and extremely successful in "teamwork". On the other hand, there are those that seem to prefer learning on their own. They usually obtain information through abstract conceptualization. These individuals are self-motivated, curious, like to test information, resort to trial and error in learning, and can learn by doing. If motivated, the latter individuals can also be active participants and often visualize themselves as group leaders. ${ }^{(20)}$ The task of forming groups in his /her course lies on the shoulder of the instructor who has to make sure that the formed group is: homogeneous, compatible, and that each and every group member has the opportunity to learn. The following statements, based on the work of Rita Dunn ${ }^{(11)}$ and recast by: Finelli, Klinger and Budny ${ }^{(7)}$, provide explanations and add meanings to the concept of learning style from different perspectives.

- Each student is unique, able to learn, and has an individual learning style.

- Individual learning styles should be acknowledged and respected.

- Learning style is a function of heredity and experience, and develops individually over one's life span.

- Learning style is a combination of affective, cognitive, environmental, developmental, and physiological responses that characterize how a person learns.

- Individual information processing, fundamental to learning style, could be improved over time with practice.

- Learning style is a complex construct for which comprehensive understanding evolves.

- Learners are empowered by knowledge of their own and others' learning styles.

- Effective teaching implies continuous monitoring to ensure compatibility of instruction with each individual's learning style.

- Teaching individuals through their learning style strengths, improves their achievement, self-esteem, and attitude toward learning. 
- Every person is entitled to counseling and instruction that is compatible with his/her style of learning.

- Applicable curriculum and teaching methods should be learning-style based and personalized to address and respect diversity.

\section{Despite the many variations of substance, content and views of learning styles, the} practice of incorporating some or all of the elements listed above in an "engineering" course, in which one is already faced with the problem of too much material in too short a time, is daunting. So the idea of teaching to easily identifiable learning styles, while superficially simple, is in reality highly complex. But the challenge is exciting to any caring instructor who wishes to "humanize" the teaching (and learning) process, and reconcile within himself /herself that: he /she is teaching students rather than "unloading" teaching material in accordance with a time schedule.

\section{Teaching Responsively}

Being a responsive teacher is part and parcel of being a caring faculty member. To teach responsively, one needs to examine how students experience their learning. It is important to know what significance students ascribe to faculty's actions, views, and concerns. For the students, faculty's choice of exercises, materials, assignments, etc.may not always be compatible with faculty's intention. Therefore, methods, content, connectedness, and goals may have to change to become more compatible with the ways these are perceived by students. Which knowledge and skills to explore next and how best to examine these, are decisions made in the midst of the teaching activity itself, rather than being planned in detail from the outset. Thus regular discussions with students concerning how aspects of the educational process might be altered to make them more meaningful are important aspects of such teaching. Negotiating and reframing sessions become familiar features of classroom life. Sometimes these sessions will lead to major shifts in directions or changes in method when the faculty member realizes that his /her activities are not having the intended effects. ${ }^{(5)}$ At other times there will be little change, but students will have had the chance to question the faculty about why he/she is doing what he /she has embarked on.

It is not easy to come to grip with all aspects of students' learning. It requires patience, time and commitment to accomplish this mission. It is important to know something about the typical rhythms of learning. The faculty wants to discover the most commonly experienced peaks and troughs, the events students remember as alienating and those they remember as affirming, and why this is so. It is helpful to get a sense of how they experience learning something new and difficult, and what helps reduce the anxiety aroused by confronting unfamiliar activities or ideas. Knowing how they react to criticism, how they deal with failure, and how they move out of a frustrating period of being stalled or blocked is crucial to teacher's practice. When the faculty has some insight into these rhythms, he/she can compensate for periods that are too frantic and can move more quickly through periods that seem lethargic. Also, can anticipate periods of frustration and anxiety and knows what signs to look for, should these occur. Faculty's knowledge, experience, and foresight are essential in overcoming problems and 
difficulties that may arise and can forestall some of these "set backs" by removing unnecessary blockages.

There are those venues, elements, perceptions, and practices that would enrich teaching/learning and, at the same time, engender the sense that the faculty is a major contributor to class work, and a facilitator and a supporter of students in and out of class. Some of these practices are explained below.

A journey of joy: A caring college professor has a clear understanding of the value of the topics and course material that he /she teaches and their impact on the professional and personal development of students. As an example, if a teacher treats applied mechanics as an end in itself, he /she is not stimulating the students in putting the material in the most meaningful context. Although the material may eventually become "second nature" to the students, they may fail to appreciate and enjoy the subject because they did not perceive its relevance and applications to their future course work and their career. This is a missed opportunity that the faculty member ought to capitalize on! And make the course enjoyable irrespective of its standing in the overall program. The perception that most students have and relate openly is: "College work is not meant to be enjoyable. College is the price you have to pay to become a professional.” If students perceive their college work this way, then the faculty is not doing his /her job properly. College Education is more than an investment. It is an open ended process- it is a journey that should be enjoyed irrespective of the final destination. ${ }^{(1)}$

An assertion of students' self-confidence: Students' performance on tests and homework is not the main issue in teaching. The important issue is how well the students learn to approach a problem or a situation, particularly a new one. It is the faculty's responsibility to expose them to the necessary tools and skills to deal with such situations, to validate their self-confidence and assert the view that they can do their own search. Students' self-confidence will diminish with criticism, mockery and lack of support. Although the material they are exposed to in the course could soon be forgotten, what students must take with them is their ability to deal with problems, their selfconfidence in their ability to seek solutions, and their understanding that it is all right to seek help and support, whenever they need to do so. The faculty member is undoubtedly responsible for creating a climate where students are not hesitant and/or afraid to ask questions, make a comment, or participate in open discussions. Additionally, a caring professor perceives that the attention given to the student answering a question is more important than the accuracy of the answer. An answer given with enthusiasm and genuine desire to convey a message or express an opinion is a reflection of student's selfconfidence. $^{(1,5)}$

Self-worth and measured performance: The more a faculty sees a student's worth is not based solely on his /her performance, the more supportive a caring faculty can be of student's learning and measurable achievements. In a caring environment a professor sees what students do as a manifestation of who they are. Each person as a whole, irrespective of position or age, is more than what others can literally see. The concept of self worth should be based on what a person is, and what the person does being a reflection of it. Actions, deeds, and accomplishments are intended to enrich the person and the person's 
life, not to define them. ${ }^{(1)}$ A person's wholeness is comprised of: virtues, passions, good deeds, character defects, etc.Take away his/her possessions and achievements and there must still be a whole person with his/her “worth”vertually intact. ${ }^{(1)}$ One’s work and achievements are meant to enrich life, to enhance creativity, and to engender the sense that a person is a contributor to his/her community. The more the professor appreciates his /her own worth and realizes that professional achievements are only an expression of one's self, the more successful that professor is likely to become.

Fostering challenge: The insight that students remember as transformative those learning episodes in which some element of challenge was involved has powerful implications for teaching. One of the most laudable characteristics of teachers is their readiness to affirm and encourage learners. Such affirmation is crucial to strengthening a student's sense of self-regard. Take to extreme, however, affirming students can lead, at times, to an educational cul-de-sac, in which students feel good about themselves but are never prompted to explore alternative perspectives, to venture into new skill areas, or to scrutinize critically those habitual assumptions underlying their thoughts and actions. Students are sometimes so enclosed within their narrow frames of reference that they are the last to recognize that these may be self-defeating or harmful. Thus the important thing that a caring faculty can do for the students is to challenge them with alternative perspectives, new activities, and critical reflection. ${ }^{(5)}$

Unpredicted changes: When the instructor makes last-minute changes that are not part of the plan (whether it is course material, exam schedule, novel approaches to teaching, etc.), the reasons for such a change need to be explained to students. This is partly a matter of common courtesy and respect. More important, though, if the instructor has a habit of saying he /she will do one thing and then do another-without explaining carefully the rationale for such a change of mind- then the instructor, as a consequence, will face the chance that the students may be at loss and may hesitate whether they should trust the instructor in the future. So, a caring instructor should leave himself /herself open to the possibility of change and follow his /her instincts even when these diverge from the plan, but ought to alert students about potential changes and informing them fully about the reasons behind the change.

Fostering a learning community: The survival metaphor often invoked by students when describing their progress through higher education focuses on the importance of learning communities. Realizing the significance of such emotionally sustaining support networks should alert faculty members to the need to seize on opportunities to assist their development when these arise. A caring faculty can assist in bringing students closer together through formation of learning partnerships, peer teaching, and sharing data and information with one another. It has been astonishing to see how working in collaborative dissertation groups has affected students. Long after their graduation, students recall the most significant aspect of their graduate program being the interpersonal learning and the development of collaborative sensitivity and mutual understanding among group members. Learning how to acknowledge differences, arrive at consensus, set limits, and administer fair sanctions to non-cooperative members are remembered and spoken of as more memorable than either the formal focus of the joint research undertaken by the group or the content of the course work in the program. The intensity of the group 
experience remains with the students long after graduation. Interestingly, this is as true for students in groups that are marked by strong disagreements and personality clashes as it is for those groups that are well integrated.

Teaching responsively is neither easy nor convenient, and runs against many assumptions, preconceptions, and beliefs. Being a responsive teacher, however, means that you should not plan objectives and methods or predict outcomes months in advance. You can not fix evaluative criteria at the start of an educational activity and expect these to be as relevant at the end as they were at the beginning. Being responsive to students' experiences of learning makes your assessments of your effectiveness as a teacher partly dependent on students' perceptions of what is taking place in the classroom. Such contextual notions of effectiveness do not always sit well with the administrative desire to standardize effectiveness through a series of replicable indicators. Trying to understand how students experience learning, analyzing one's own practice to attempt to take account of this understanding, and reframe one's objectives, methods, and evaluation criteria as the dominant themes or concerns emerging from the students and the classroom set up, is complex, ambiguous, and most likely incompatible with institutional plans and practices. Although the efforts required are substantial, but, so are the rewards. At the very least the teacher will be alerted to common rhythms of learning and to the ways and means of changing course, should the need arises. ${ }^{(21)}$ As a consequence, the teacher will be less likely to make some of the more frequent mistakes that arise when teachers underestimate the complexity of learning. Most importunately is that teachers will no longer pursue the illusive concept that one method of teaching is suitable to all settings, purposes, and students.

\section{Building Trust with Students}

Underlying almost all aspects of learning is the element of trust. Trust between teachers and students is the affective glue binding educational relationships together. Not trusting teachers has serious consequences for students. Students are unwilling to submit themselves to the uncertainties of novel and unfamiliar approaches to learning. They do want to avoid risks and keep their deeply felt concerns private. The more profound and meaningful the learning is to students, the more they need to trust their teachers. ${ }^{(5)}$ The importance of trust is experienced, time and time again, in students' critical incident responses, i.e., when students are off track and/or lose patience, and reach the stage where they can no longer exercise good judgment; then, they do need the care and attention of their teachers. At the center of the cluster of characteristics that make teachers more trustworthy in studets' eyes are two components that may be described as teacher credibility and teacher authenticity.

Teacher credibility: Teacher credibility refers to teacher' ability to present himself/ herself as a person with something to offer to students. When teachers have this credibility, students see them as possessing a breadth of knowledge, depth of insight, and richness of experience that far exceeds the students' own. Shor and Friere ${ }^{(22)}$ describe credibility as the "critical competence" that students have the right to expect of their teachers. Almost all students continually stress their desire to be in the presence of someone who is knowledgeable, skilful and an expert in his /her field, i.e., meaning that 
he/she can help students come to grips with the contradictions, complexities, and problems they are experiencing.

Teacher authenticity: Authentic teachers are those that students feel that they can trust. (23) They are also those whom students see as human beings with passion, frailties, and emotions. They are remembered as whole persons, not as people who hide behind a collection of learned role behaviors appropriate to college teaching. In more specific terms, students see four types of behavior as evidence of authenticity: i) teachers words and actions are congruent; ii) teachers admit to error, acknowledge fallibility, and do make mistakes in public view of learners; iii) teachers allow some aspects of their personality ( outside their role as teachers) to be revealed to students; and iv) teachers do respect learners by allowing them to express their views and by being open to changing their practice as a result of students’ suggestions.

Steps towards trust buildings: Trust is not something bestowed on teachers just because they are teachers, it must be earned! Undoubtedly, it takes time, effort, and willingness on the part of the teacher to earn the trust of the students. Teachers must remember that not only can they not expect students to trust them from the outset; they most likely have to face accumulations of mistrust nurtured by actions of cynical, arrogant, and indifferent teachers in students' past. This is likely to arise when the teacher is facing the students for the first time; and face also their accumulated educational histories and their memories of the teachers they have experienced in the past. Building trust is neither quick nor easy. It may be very dispiriting to realize that one's efforts to build trust with his/her students may often bring little immediate results. With patience and persistance, however, and with the advice of those teachers with experience, it is possible to build trust where none has existed before. Undoubtedly, students will remember the time they spent with a caring faculty who has done his/her level best to understand and be of help to them. There are those steps and /or precautionary measures that teacher should be aware of and attempt to follow, if and when the need arises. These include:

First, Denial of one's credibility: Teachers' protestations that they don't really know any more than students do and that they are simply there to help students realize that they already possess all the knowledge and skills they need. If students conclude that teachers' experiences have left them with no greater skill, knowledge, or insight than that already possessed by them, then there is nothing useful to gain from teachers. Teachers should be careful not to undermine their own credibility in the eyes of their students.

Second, Be explicit about one's organizing vision: It is quite normal to have visions that guide the practice. However, when teachers deny having any visions, plans, or educational agenda, yet through their actions do make it apparent that such visions exist and do influence classroom activities. Not to be explicit about teachers' vision, plans, and agenda, at the outset, confuses students and is fundamentally wrong. ${ }^{(5)}$ Therefore, should be avoided.

Third, The congruence of words and actions: Few things destroy students' trust in teachers more quickly than teachers who say they will do one thing and proceed to do something very diffenrent.Or, teachers who espouse one set of plans and principles then proceed to implement something else. Teachers ought to be careful and take necessary measures to safeguard themselves against falling in this trap. 
Fourth, Be willing to admit that you make mistake: Teachers who acknowledge that they do not have all the answers and that, like their students, they sometimes feel out of control. Such acknowledgement helps reduce the tension students feel about their own need to be seen as perfect by their peers and teachers. While declarations of fallibility from teachers who earned credibility are appreciated by the students, the same declarations from those teachers who have not earned their credibility as yet - are basically unknown quantities- may produce the opposite effect of the one intended. Fifth, Revealing aspects of one's self unrelated to teaching: Nothing wrong when teachers refer to enthusiasms, passions, and concerns outside his /her teaching role. Revealing aspects of one's personhood gives students a sense that they are in the presence of an ordinary person; thus helps in bridging the gap that may have developed between students and their teachers. Often, teachers use incidents from their own daily lives to illustrate general principles, and talk about those passions that led them to develop an interest in their fields, and in reference to their own extracurricular enthusiasms that sustain and renew these interests. ${ }^{(5,21)}$

Sixth, Show that you take students seriously: A caring teacher should listen carefully to any concerns, anxieties, or problems voiced by the students. If none are forthcoming, the teacher should find opportunities and encourage students to speak out their minds and express their concerns - no matter how misplaced or trivial it may be- without interruption, rephrasing, or interpreting their concerns. Even if the teacher is confused about what a student is saying, he /she should be patient and chances are that the same concern will be expressed by another classmate in a clearer manner. When students suggest topics, exercises, and issue they wish to explore, even if these are outside the original scope, the teacher should consider seriously how to make some compromise to include some of what has been suggested by the students. ${ }^{(21)}$

Seventh, shouldn't play favorites: Almost in every class there are those students that the teacher prefers to listen to more than others, people whose work he /she looks forward to receiving, and those whom he /she would welcome as personal freinds.Convesely, there are those whom the teacher may dislike personally, and whom he /she thinks are "boring", insensitive, and do not give the course the effort and attention it requires. As a human being, it is normal to warm up for some and freeze in the presence of others. But if the teacher is to be trusted by all students, it is absolutely essential that he /she does not allow himself /herself the luxury of exercising these personal dislikes, and definitely needs to avoid playing favorites. Playing favorites-showing that he/she regards some people work more favorably because of their appealing personalities and prejudiced against other's efforts for their personal attitudes-destroys one's credibility in students' eyes very quickly. ${ }^{(5,21)}$

The concepts of credibility, authenticity and the suggested steps towards building trust between students and their teacher are elusive, and made the more so by the fact that they are not standardized. It is not possible to develop ways of telling people how to be credible or authentic, since contextual features affect so strongly how students and teachers define credible and authentic behaviors. The most that could be done is to offer guidelines, give examples of how teachers in different environments try to build trust, and urge those teachers, who wish to benefit from such experience, to pay attention and try to implement some of the guidelines mentioned earlier. Teaching with care is not easy, and all of the potential balances a teacher is encouraged to try to attain being 
credible and authentic in the right proportions is a difficult task. But caring teachers should not be discourage, give up, or neglect the need to build credibility in students' eyes, then, chances are that students will have little confidence in the value of what the teacher asks them to do. And if the teacher behaves inauthentically, students will regard teacher's asking them to do it as a self-serving confidence trick.

\section{Concluding Remarks}

All of us, in higher education, like to think of ourselves as caring professors, and who's to say we are not. How can an outsider (e.g., a researcher, an administrator) come forward and say that he or she knows what is going on inside of us, as professors? Is caring something that each one of us must privately determine whether or not we experience? And does it vary in levels or degrees, so that I could be a caring professor as much as I deem is necessary, right, or humanly possible, and another professor could be caring to an entirely different level, that I would not feel comfortable with or even find possible? Does that make me a worse or less caring teacher? These kinds of issues have to be addressed when one attempts to confront a topic such as "caring." It is a personal, subjective topic full of passions and feelings that not many researchers choose to tackle. Yet, it is our contention that faculty members who care about their students are remembered, effect change, stimulate development, and are more likely to be successful at teaching their students. As a result, focusing on caring as a topic of research is undoubtedly important.

It is part of the caring professor's craft to learn how to make choices about which methods and materials to use, how to pace educational activities, or what evaluative criteria are most appropriate. Also, he /she needs evidence about how students perceive and respond to his/her actions. If the professor wants to teach responsively, and if he/she wants his/her adjustments, shifts, and changes to have the intended positive effects, then he/she must first of all have as full and complete understanding as he /she could of how students experience learning. To prepare one's self for the potential role as a caring teacher, he /she needs to gain the insight, the knowledge, and the skills discussed earlier in this manuscript. How can this be done? Four domains are of particular importance:

i) Developing critical rationale for good teaching,

ii) Understanding and taking account of learning styles,

iii) Examining how to make one's teaching more responsive to students' needs, and

vi) Embarking on specific measures to build trust with students.

As a caring and responsive teacher, one's practice exhibits a constant interplay between action and analysis, along with evaluative criteria as the teacher gets to know more about new settings, newly adopted methods and skills, and the ways these are perceived by students.

One of the best ways to improve one's teaching is to experience, and to remember, what it feels like to learn something, especially something new and difficult. Reflecting on the experience of learning has very powerful implications for one's own teaching. It will make the teacher aware of the behaviors that affirm and encourage students and those that intimidate and hinder them. It will give the teacher new insight into why and how students resist learning and what some useful responses to this resistance might be. 
Teachers should try to alert their institutions to mount a faculty development effort in which teachers experience learning individually and then come together in reflective groups to consider the implications of these experiences for their own teaching.

\section{Bibliography}

1. Haddock, Jorge, “Profile of a Nurturing College Professor," Engineering Education, Vol.82 no.1, 1993, pp.34-37.

2. Peck, M.S., The Road Less Traveled, Simon and Schuster, New York, 1978.

3. Eble, K. E., The Aims of College Teaching, Jossey -Bass, San Francisco, 1983.

4. Mckeachie, W., Pintrich, P., Yi- Guang, L., and Smith, D., Teaching and Learning in the College Classroom: A Review of the Research Literature, Ann Arbor, Mich.: The Regents of the Univ. of Michigan, 1986.

5. Brookfield, S. D., The Skillful Teacher, Jossey -Bass, San Francisco, 1990.

6. Brown, G. A., and Atkins, M., Effective Teaching in Higher Education, New York: Methuen, 1987.

7. Finelli, C., Klinger A., \& Budny, D.D., "Strategies for Improving the Classroom Environment," Journal of Engineering Education, Vol. 90, no.4, 2001, pp. 491-497.

8. Myers, I.B. \& McCaulley, M.H., A Guide to the Development and Use of the Myers- Briggs Indicator. Palo Alto, CA: Consulting Psychologists Press, Inc., 1985.

9. Kolb, D.A., Experiential learning: Experience as the Source of Learning and Development. Englewood Cliffs, CA: Prentice Hall, 1984

10. Felder, R.M., Reaching the Second Tier: Learning and Teaching Styles in College Science Education. Journal of College Science Teaching, Vol. 23, no.5, 1993, pp. 286-290.

11. Dunn, R., Understanding the Dunn and Dunn Learning Styles Model and the Need for Individual Diagnosis and Prescription, Reading, Writing and Learning Disabilities, Vol.6, 1990, pp. 223-247.

12. Wankat, P.C., Reflective Analysis of Student Learning in a Sophomore Engineering Course, Journal of Engineering Education, Vol. 88, (no.2), 1999, pp. 195-203.

13. Fairhurst, A.M., \& Fairhurst, L.L. (1995). Effective Teaching, Effective Learning. Palo Alto, CA: Davies-black Publishing, 1995.

14. Culver, R.S., and Hackos, J.T., Perry's Model of Intellectual Development. Journal of Engineering Education, Vol.73, 1982, pp. 221-226.

15. Ramsden, P., Learning to Teach in Higher Education, London, UK: Routladge, 1992.

16. Marton, F., \& Saljo, R., Approaches to Learning. In Marton, F. et al. (editors).The Experience of Learning. , Edinburgh, Scotland: Scottish Academic Press, 1984.

17. Tendy, S.M., and Geiser, W.F. (1998). The Search for Style: It All Depends on Where You Look. National FORUM of Teacher Education Journal, Vol.9, (no.1), 1998, pp. 3-15.

18. McCaulley, et al., Application of Psychological Type in Engineering Education. Engineering Education, Vol. 73, (no.5), 1995, pp. 394-400.

19. Klinger, A., Finelli, C. J.and Budny, D.D., "Improving the Classroom Environment," 30th Annual IEEE/ASEE Frontiers in Education Conf., Kansas City, MO., 2000.

20. Tobias, S., They're Not Dumb, They're Different: Stalking the Second Tier. Long Branch, NJ: Science News Books, 1994.

21. .Brookfield, S. D., Grounding Teaching in Learning. In M. Galabraith (ed.), Facilitating Adult Learning: A Transactional Process. Melbourne, Fla.: Kreiger, 1990.

22. Shor, I., and Freire, P.A., Pedagogy for Liberation: Dialogues on Transforming Education. Granby, Mass.: Bergin \& Garvey, 1987.

23. .Moustakas, C., The Authentic Teacher: Sensitivity and Awareness in the Classroom. Cambridge, Mass.: Howard A. Doyle, 1966 